Bond between ribbed bars and concrete. Part 2: The effect of corrosion K. Lundgren

Published in Magazine of Concrete Research, see journal homepage http://www.icevirtuallibrary.com/content/journals

"Permission is granted by ICE Publishing to print one copy for personal use. Any other use of these PDF files is subject to reprint fees." 


\title{
Bond between ribbed bars and concrete. Part 2: The effect of corrosion
}

\author{
K. Lundgren \\ Chalmers University of Technology, Göteborg, Sweden
}

The corrosion products that form when reinforcement in concrete corrodes occupy a larger volume than the steel it was formed of, thus leading to splitting stresses acting on the concrete. Thereby, the bond between the reinforcement and the concrete is influenced. A model of the corrosion was developed by the author in earlier work. This was used together with a modified model of the bond mechanism, presented in a companion paper, in three-dimensional finite element analyses where both the reinforcement and the concrete were modelled with solid elements. Several corrosion cracking tests, beams and pull-out tests with corroded reinforcement, both with and without transverse reinforcement, carried out by various researchers, were analysed by using the corrosion model. The results were compared, and reasonably good agreement was found. Furthermore, the model was used to study the effect of uniform or localised corrosion. It was shown that for localised corrosion, less average corrosion penetration was needed to crack the cover than for uniform corrosion; in addition, the crack pattern differed. From these analyses, it was concluded that axisymmetric analyses appear to be a sufficient level of modelling when studying cracking due to uniform corrosion. If localised corrosion is to be studied, three-dimensional models need to be used. The model was also used to study the effect of uniform corrosion on the anchorage length when no transverse reinforcement is present. Under these circumstances, the criterion 'the anchorage of the reinforcement becomes critical when cracking of the cover occurs' was shown to be on the safe side to use.

\begin{tabular}{|c|c|}
\hline \multicolumn{2}{|c|}{ Notation } \\
\hline$a$ & free increase of the radius due to corrosion \\
\hline$E_{\mathrm{s}}$ & Young's modulus for steel \\
\hline$f$ & $\begin{array}{l}\text { possible increase of the radius before any } \\
\text { normal stresses are applied to the } \\
\text { surrounding concrete }\end{array}$ \\
\hline$p_{\mathrm{m}}$ & the porosity of the mortar \\
\hline$t_{\text {in }}$ & the thickness of the mortar-rebar interface \\
\hline$t_{\mathrm{n}}$ & normal stress \\
\hline$t_{\mathrm{t}}$ & bond stress \\
\hline$u_{\mathrm{n}}$ & relative normal deformation \\
\hline$u_{\text {ncor }}$ & $\begin{array}{l}\text { normal deformation in the corrosion layer; } \\
\text { i.e. increase of the radius due to corrosion }\end{array}$ \\
\hline$u_{\text {ncor,crack }}$ & $\begin{array}{l}\text { the deformation of the corrosion layer when } \\
\text { the cover cracks }\end{array}$ \\
\hline$u_{\text {nbond }}$ & normal deformation in the bond layer \\
\hline
\end{tabular}

* Department of Civil and Environmental Engineering, Division of Structural Engineering, Concrete Structures, Chalmers University of Technology, SE-412 96 Göteborg, Sweden.

(MCR 31131) Paper received 29 April 2003; last revised 27 January 2004; accepted 24 February 2004

\begin{tabular}{|c|c|}
\hline$u_{\mathrm{t}}$ & slip \\
\hline$v$ & volume rust /volume steel \\
\hline$w / c$ & water/cement ratio \\
\hline$x$ & corrosion penetration \\
\hline$\alpha$ & degree of hydratation \\
\hline$\delta_{\text {crack }}$ & $\begin{array}{l}\text { the deformation of the hole that causes } \\
\text { cracking of the cover }\end{array}$ \\
\hline$\delta_{\text {reinf }}$ & $\begin{array}{l}\text { the deformation of the reinforcement bar due } \\
\text { to a normal pressure }\end{array}$ \\
\hline$\varepsilon$ & strain \\
\hline$\kappa$ & hardening parameter \\
\hline$\nu_{\mathrm{S}}$ & Poisson's ratio for steel \\
\hline
\end{tabular}

\section{Introduction}

Corrosion of the reinforcement often limits the service life of concrete structures. Usually, when estimating their service life, it is divided into an initiation period (the time before corrosion of the reinforcement starts) and a propagation period (the time before a maximum of allowable corrosion has occurred). The most common causes of initiation of corrosion are carbonation and chloride ion ingress. With the help of 
models of how fast the carbon dioxide or the chloride penetrates through the concrete cover, the initiation period can be determined. By estimating the corrosion rate and the maximum allowable corrosion, the propagation time can be determined, and thereby the service life of the concrete structure. This paper will concentrate on models that are needed when the maximum allowable corrosion is to be determined. Then the effect of corrosion on the load-bearing resistance of the structure needs to be determined.

Corrosion of the reinforcement in concrete structures causes two effects: (1) the cross-sectional area of the reinforcement decreases. The effect of this on the loadbearing resistance is rather easy to take into account: in principle the same models as for undamaged concrete structures can be used, only with a reduced area for the reinforcement. (2) The corrosion products occupy a larger volume than the steel it was formed of. This leads to splitting stresses acting on the concrete, which might cause spalling of the cover. The latter affects the structure in several ways. On the compressed side of a structure, spalling of the cover will lead to a decrease of the internal lever arm, which in turn decreases the bending moment capacity. Furthermore, the interaction between the reinforcement and the concrete is influenced. This interaction is commonly called the bond mechanism. Due to the effect on the bond mechanism, the deformations increase, and if the corrosion takes place in certain parts of the structure, such as at supports and at splices, the load-bearing resistance will be influenced.

The effect of the volume increase is not so easy to take into account when calculating the load-bearing resistance of corroded reinforced concrete structures. A model of the corrosion together with a model of the bond mechanism was developed by the author in earlier work. ${ }^{1}$ The bond model, however, was shown to generate energy for some special loading-unloading sequences (Gustafsson P. J., pers. Comm., 2002). To avoid this undesirable effect, the formulation of the bond model was modified; see the companion paper. ${ }^{2}$ In this paper, the calibration of the corrosion model is further investigated. Moreover, the corrosion model is used together with the bond model for analyses of several tests found in the literature. Finally, the models are utilised in analyses to provide background for design recommendations.

\section{Modelling of corrosion and bond}

The modelling method used is specially suited for detailed three-dimensional finite element analyses, where both the concrete and the reinforcement are modelled with solid elements. Special interface elements were used at the surface between the reinforcement bars and the concrete to describe a relation between the traction $\mathbf{t}$ and the relative displacement $\mathbf{u}$ in the interface. The physical interpretations of the variables are as follows

$$
\begin{array}{r}
\mathbf{t}=\left[\begin{array}{c}
t_{\mathrm{n}} \\
t_{\mathrm{t}}
\end{array}\right]=\left[\begin{array}{c}
\text { normal stress } \\
\text { bond stress }
\end{array}\right] \\
\mathbf{u}=\left[\begin{array}{c}
u_{\mathrm{n}} \\
u_{\mathrm{t}}
\end{array}\right]=\left[\begin{array}{c}
\text { relative normal displacement } \\
\text { slip }
\end{array}\right]
\end{array}
$$

The corrosion model and the bond model can be viewed as two separate layers around a reinforcement bar. However, to reduce the number of nodes required to model a structure, they are integrated in one interface element. Due to equilibrium between the two layers, the traction $\mathbf{t}$ is the same in the bond and in the corrosion layer. The deformations are related as

$$
\begin{gathered}
u_{\mathrm{n}}=u_{\mathrm{ncor}}+u_{\text {nbond }} \\
u_{\mathrm{t}}=u_{\text {tbond }}, u_{\text {tcor }}=0
\end{gathered}
$$

where the index 'cor' refers to the corrosion layer, and the index 'bond' refers to the bond layer. The bond model used is presented in the companion paper.

\section{Corrosion model}

The volume increase of the corrosion products compared to the virgin steel was modelled in a corrosion layer, as described in Lundgren. ${ }^{1}$ The volume of the rust relative to the uncorroded steel, and the corrosion penetration as a function of the time, were given as input. The corrosion was then modelled by taking time steps.

The physical interpretation of the variables in the corrosion model is shown in Fig. 1. The free increase of the radius, namely how much the radius would increase if the normal stresses were zero, is calculated from

$$
a=-r+\sqrt{r^{2}+(v-1) \cdot\left(2 r x-x^{2}\right)}
$$

where $v$ is the volume of the rust relative to the uncorroded steel, which was assumed to be $2 \cdot 0$. The real increase of the radius is $u_{\text {ncor }}$, corresponding to a strain in the rust

$$
\varepsilon_{\mathrm{cor}}=\frac{u_{\mathrm{ncor}}-a}{x+a}
$$

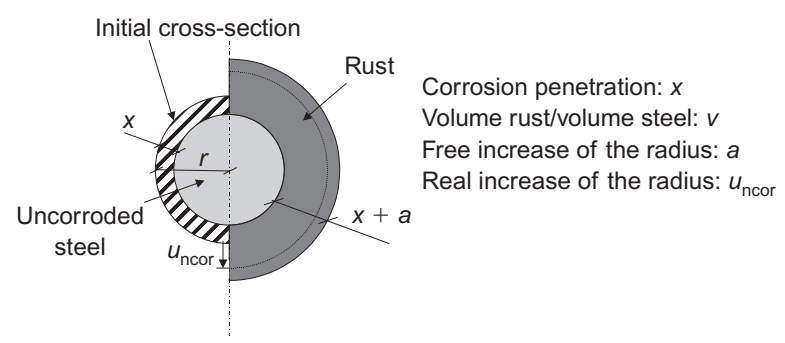

Fig. 1. Physical interpretation of the variables in the corrosion model

Magazine of Concrete Research, 2005, 57, No. 7 
From this strain in the rust, the normal stresses in the layer are determined.

To investigate the mechanical behaviour of rust, experimental results in corrosion cracking tests found in the literature were combined with finite element analyses, as outlined in Fig. 2. The corrosion penetration that causes cracking of the concrete cover has been measured by several researchers, for various types of specimens. These specimens were analysed by using finite element modelling and non-linear fracture mechanics for the concrete. Only the concrete of the specimens was modelled, with a hole where the reinforcement was situated. A normal deformation was applied at the hole, resulting in a normal stress versus deformation curve typical for the specimen. From each analysis, the normal stress and deformation of the hole that caused cracking of the cover were used. This, in combination with the experimentally measured corrosion penetration that caused cracking, results in one point in a stress versus strain diagram.

To evaluate the strain in the rust, the deformation of the corrosion layer when the cover was cracked, $u_{\text {ncor,crack, needs }}$ to be determined. It was calculated from the deformation of the hole that caused cracking of the cover, $\delta_{\text {crack }}$, taking into account that the reinforcement bar and the bond layer are also slightly compressed due to the normal stress. The deformation of the reinforcement bar due to a normal pressure $-t_{\mathrm{n}}$ acting on it can be calculated as

$$
\delta_{\text {reunf }}=\frac{t_{\mathrm{n}}}{E_{\mathrm{s}}} \cdot r\left(1-v_{\mathrm{s}}-2 v_{\mathrm{s}}^{2}\right)
$$

where $E_{\mathrm{s}}$ and $v_{\mathrm{s}}$ are the Young's modulus and the Poisson ratio for steel. They were assumed to be
$200 \mathrm{GPa}$ and $0 \cdot 3$, respectively. The deformation of the bond layer can be calculated as

$$
u_{\text {nbond }}=\frac{t_{\mathrm{n}}}{D_{11}\left(u_{\text {nbond }} \leqslant 0\right)}
$$

where $D_{11}\left(u_{\text {nbond }} \leqslant 0\right)$ is the elastic stiffness $D_{11} ; u_{\text {nbond }}$ will be smaller than zero since the bond layer will be compressed without any slip applied. The deformation $u_{\text {ncor,crack }}$ can then be calculated as

$$
u_{\text {ncor,crack }}=\delta_{\text {crack }}-\delta_{\text {reinf,crack }}-u_{\text {nbond,crack }}
$$

These effects were assumed to be negligible in earlier work (Lundgren ${ }^{1}$ ); however, they did have some influence on the results, leading to slightly smaller evaluated strains in the rust. In Fig. 3(a), the modified results are shown as points in a stress versus strain diagram. Still, it appears reasonable to assume that the rust behaves like a granular material; namely its stiffness increases with the stress level. The mechanical behaviour of the rust at loading could be described with the equation

$$
t_{\mathrm{n}}=K_{\mathrm{cor}} \cdot \varepsilon_{\mathrm{cor}}^{p}
$$

In earlier work, the parameters $K_{\text {cor }}$ and $p$ were chosen to be $K_{\text {cor }}=7 \cdot 0 \mathrm{GPa}$ and $p=7 \cdot 0$. However, when the effect of the deformations of the reinforcement and the bond layer was taken into account, the value of $K_{\text {cor }}$ was adjusted to $K_{\text {cor }}=14.0 \mathrm{GPa}$, to better fit the results; see Fig. 3(a). The parameter $p$ was kept to $p=7 \cdot 0$.

\section{Alternative modelling including the effect of a low-} porosity zone close to the reinforcement bar

Several researchers, for example Noghabai ${ }^{3}$ and Petre-Lazar, ${ }^{4}$ have assumed that the corrosion products

\section{Theoretical results}

Analyses of the various corrosion cracking tests give the expansion and the normal splitting stress at cracking.

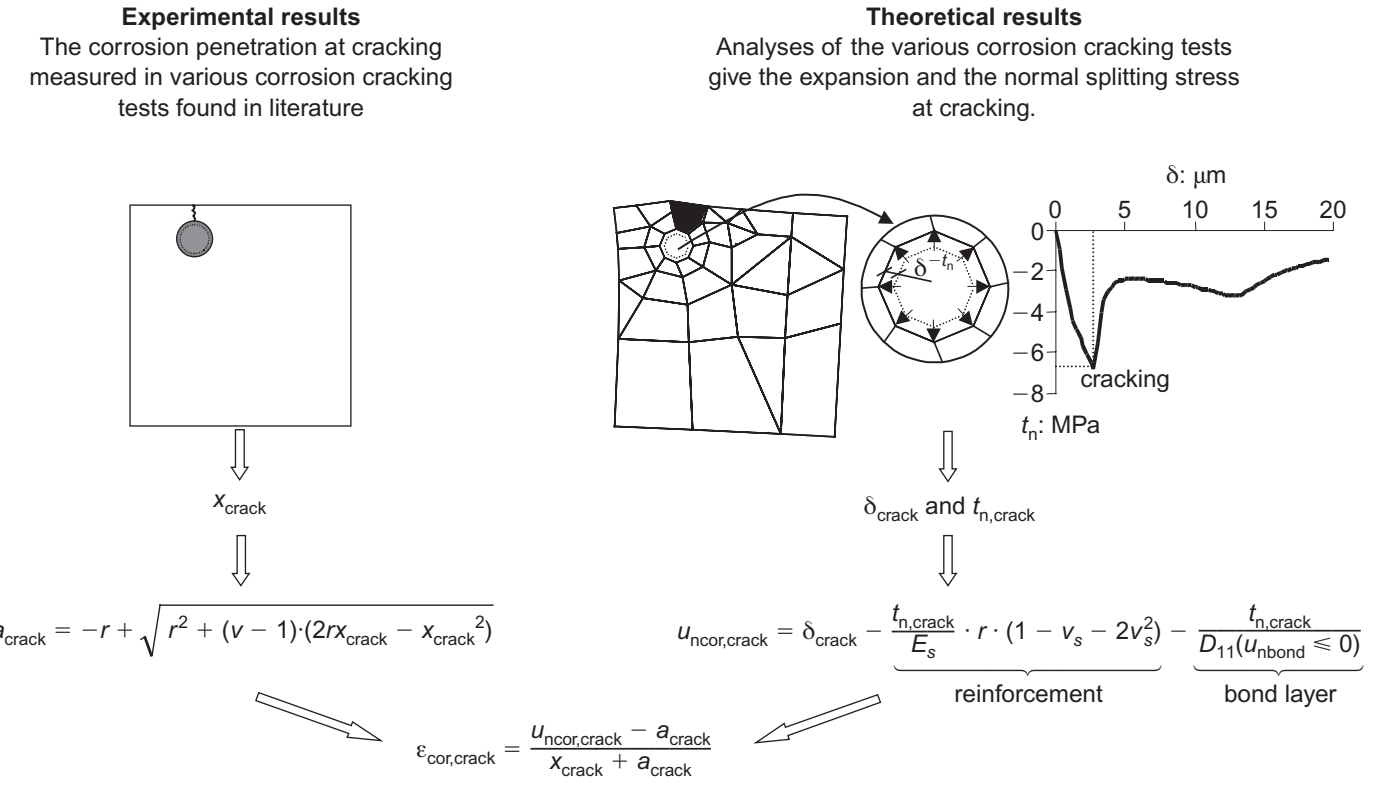

Fig. 2. Schematic view of how one point in the stress versus strain diagram for the rust is obtained from a combination of experimental and theoretical results 


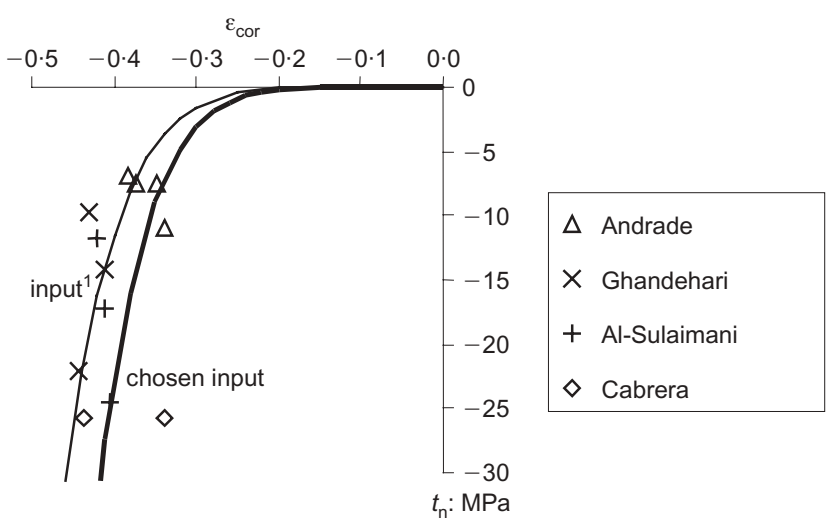

(a)

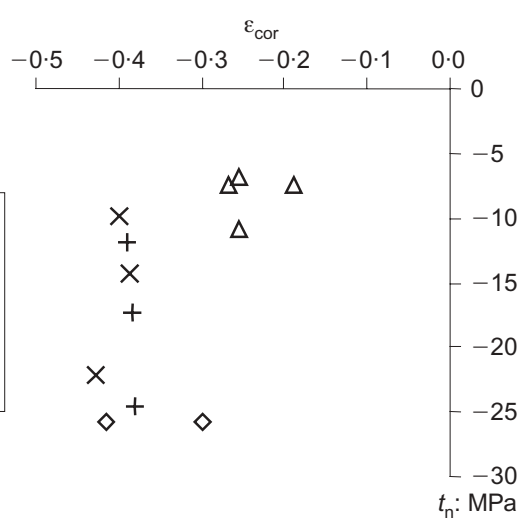

(b)

Fig. 3. Normal stress versus strain in the rust evaluated from a combination of experimental results and analyses: (a) assuming that the rust applies a pressure on the surrounding structure already from the beginning, together with the chosen input; and (b) assuming that the rust fills the pores close to the reinforcement bar before applying stresses on the surrounding structure

are infinitely stiff. Petre-Lazar ${ }^{4}$ pointed out the possibility for rust to fill up the pores close to the reinforcement bars before starting to apply stresses in the structure. He therefore divided the mechanical action of the corrosion process into two phases:

In the first phase, the porosity of a mortar-rebar interface is filled with corrosion products without applying any stresses on the surrounding concrete.

When the porosity of the mortar-rebar interface is filled, normal stresses are applied to the surrounding concrete.

This means that a certain increase of the radius occurs before any normal stresses are applied to the surrounding concrete. Petre-Lazar ${ }^{4}$ gives a method for how to estimate this distance (here denoted $f$ )

$$
f=t_{\text {in }} \cdot p_{\mathrm{m}}
$$

where $t_{\text {in }}$ is the thickness of the mortar-rebar interface, for which Petre-Lazar ${ }^{4}$ used a value of $40 \mu \mathrm{m}$, based on observations with scanning electron microscope, and $p_{\mathrm{m}}$ is the porosity of the mortar, calculated as half of the porosity of the cement paste

$$
p_{\mathrm{m}}=\left(1-\frac{1+1 \cdot 31 \alpha}{1+3 \cdot 2 w / c}\right) / 2
$$

where $\alpha$ is the degree of hydration and $w / c$ is the water/cement ratio.

The effect of this distance $f$ can be taken into account in the evaluation of the mechanical properties of the rust by changing equation (7) to

$$
u_{\text {ncor,crack }}=\delta_{\text {crack }}-\delta_{\text {reinf,crack }}-u_{\text {nbond,crack }}+f
$$

The strain in the rust at cracking for different test specimens is recalculated in this way, thus including the effect of filling up the pores close to the reinforcement bars before starting to apply stresses in the structure. The estimated values of the water/cement ratio and degree of hydration are given in Table 1, where results from both calculation methods are summarised.
The results from the analyses including the effect of the pores are also shown in a stress versus strain diagram in Fig. 3(b). If the corrosion products were infinitely stiff, all points in this diagram would be close to the zero strain line. However, this is not the case; instead large strains are evaluated. Comparing the results calculated with the two different assumptions (i.e. Figs. 3(a) and (b)), there appears to be more scatter in the results where the effect of filling up the pores is included. Therefore, the modelling method chosen was that in which the stresses due to the corrosion products are applied from the beginning, namely without the effect of the pores. It should be noted that there might be a difference between localised and uniform corrosion in this sense. Chloride-induced, localised corrosion normally starts in the location of entrapped air voids at the steel-concrete interface. These voids are typically a few millimetres in diameter, that is around 2 orders of magnitude larger that the $40 \mu \mathrm{m}$ effect associated with capillary porosity described by Petre-Lazar. The entrapped air void content is typically only a few percent and so is unlikely to be significant for uniform corrosion, but may be important for chloride-induced, localised corrosion.

\section{Effect of corrosion on friction in the bond model}

The input parameters for the bond model were given as described in the companion paper. Moreover, these input parameters were complemented with an assumption that corrosion was assumed to affect the coefficient of friction in the bond model. In earlier work (see Lundgren ${ }^{1}$ ), the coefficient of friction was assumed not to be affected by corrosion of the reinforcement. This was then found to be a valid assumption for the tests modelled therein. However, when tests with larger corrosion penetrations were investigated, it was found that the influence of the corrosion on the friction was not negligible. Therefore, corrosion of the reinforcement was assumed to affect the friction; for small corrosion penetrations, a slight increase in the friction was as-

Magazine of Concrete Research, 2005, 57, No. 7 


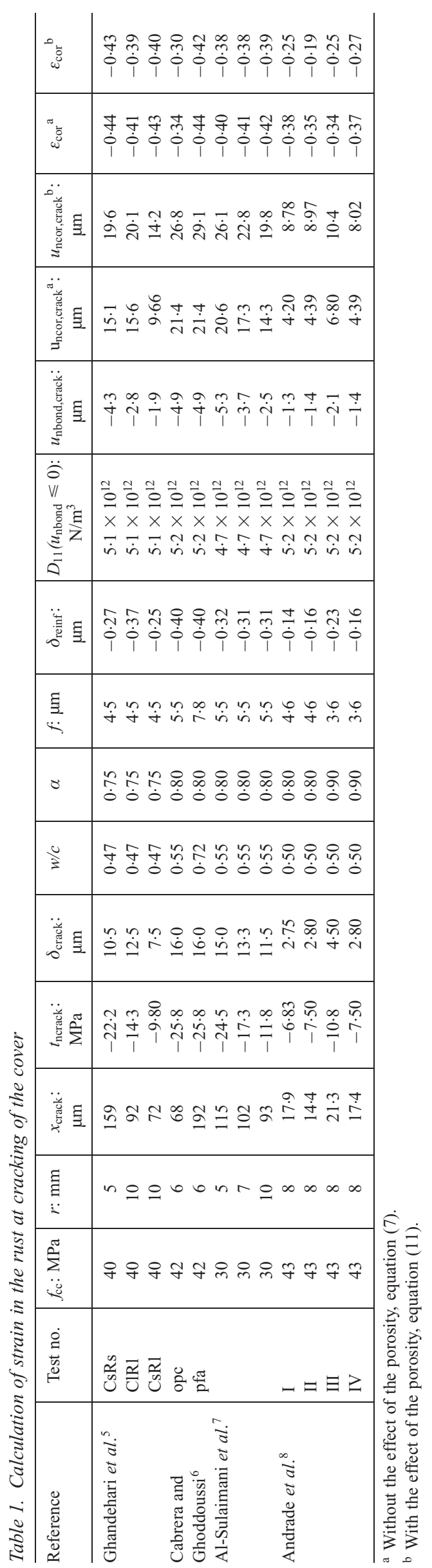

sumed, whereas for larger corrosion penetrations, the friction was decreased, as suggested in Reference 9. This was done by introducing a function $k(x / r)$ and letting the coefficient of friction be calculated as

$$
\mu(\kappa)=k(x / r) \cdot \mu_{0}(\kappa) \text {, but } \mu(\kappa) \geqslant 0 \cdot 4
$$

where $\mu_{0}(\kappa)$ is the function chosen for the coefficient of friction for uncorroded reinforcement. The function $k(x / r)$ was chosen as shown in Fig. 4, where also the resulting function $\mu(\kappa)$ for some corrosion levels is plotted.

\section{Comparison with tests}

\section{Finite element analyses}

Tests of various kinds with corroding reinforcement were analysed with finite element models. In all analyses, the concrete was modelled with a constitutive model based on non-linear fracture mechanics. In analyses using the smeared crack concept, a rotating crack model based on total strain was used. ${ }^{10}$ For the axisymmetric models, four discrete radial cracks were assumed.

From the various measured compressive strengths, an equivalent compressive cylinder strength, $f_{\mathrm{cc}}$, was evaluated. Other necessary material data for the concrete were estimated according to the expressions in $\mathrm{CEB}^{11}$ from $f_{\text {cc }}$. For the tests where information about storage and age at testing was available, shrinkage was included in the models in an approximate way, by applying uniform shrinkage calculated according to CEB. ${ }^{11}$ For these tests, the development of the compressive strength with time was also taken into account, by use of the formulae in CEB. ${ }^{11}$ The tensile strength and the fracture energy were assumed to have a similar development; that is, they were estimated according to the expressions in $\mathrm{CEB}^{11}$ from the $f_{\mathrm{cc}}$ relevant at the time. Creep and effect on strength of sustained load were not included, since these effects were not possible to combine with the chosen material model. The effect of excluding creep and sustained load is not easy to predict: on one hand, as the normal stress, $t_{\mathrm{n}}$, is sustained it can be expected to result in earlier cracking. On the other hand, creep will lead to larger deformations, $u_{\mathrm{n}}$, which will decrease the applied normal stress, $\left|t_{\mathrm{n}}\right|$, and thus later cracking can be expected. Thus, the total effect of creep and sustained load depends on these two effects, which counteract each other.

The constitutive behaviour of the reinforcement steel was modelled by the Von Mises yield criterion with associated flow and isotropic hardening. The elastic modulus of the reinforcement was assumed to be $200 \mathrm{GPa}$.

\section{Corrosion cracking tests}

Corrosion cracking tests have been carried out by several researchers. Analyses of several such corrosion 


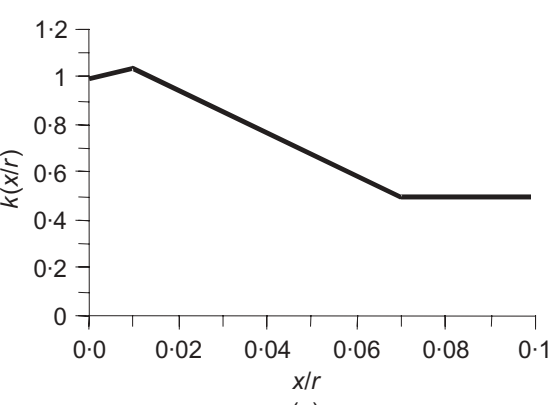

(a)

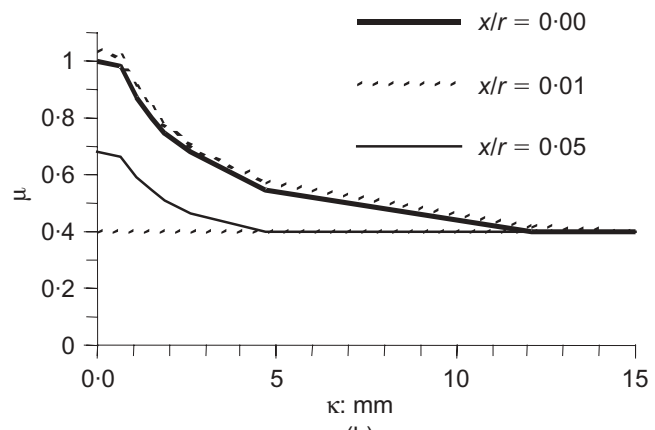

(b)

Fig. 4. (a) The chosen function $k(x / r)$ and (b) the resulting function $\mu(\kappa)$ for some corrosion levels

cracking tests were conducted, to compare the corrosion level that caused cracking of the cover in the tests and in the analyses. In all analyses, both the concrete and the reinforcement bars were modelled with solid elements, using interface elements with the specially developed corrosion and bond model in between. Here follows a brief presentation of all the analysed tests.

Andrade et $a l^{8}{ }^{8}$ carried out corrosion cracking tests with specimens of size $15 \mathrm{~cm} \times 15 \mathrm{~cm} \times 38 \mathrm{~cm}$. In these tests, current was used to induce corrosion, in combination with addition of $\mathrm{CaCl}_{2}$ to the concrete mix. Here, slices of these tests were analysed, assuming fixed boundaries in the third direction, corresponding to a plane strain assumption. In the tests where the reinforcement bar was placed symmetrically, discrete crack elements were used, while for the test where the reinforcement bar was placed in a corner, the smeared crack model was used.

Al-Sulaimani et al. ${ }^{7}$ and Cabrera and Ghoddoussi ${ }^{6}$ have carried out pull-out tests on corroded reinforcement bars concentrically placed in concrete blocks. In both investigations, current was used to accelerate corrosion. Here, the first part of their experiments was studied, namely when the reinforcement corroded until the specimen was cracked. The test specimens were approximated with axisymmetric finite element models.

Ghandehari et al..$^{5}$ used test specimens with corroded reinforcement bars in concrete cylinders. Three of their specimens were cracked during the accelerated constant current corrosion: with cylinder diameters of $100 \mathrm{~mm}$ and rebar diameters of 9.5 and $20 \mathrm{~mm}$, and cylinder diameters of $150 \mathrm{~mm}$ and rebar diameters of $20 \mathrm{~mm}$. Axisymmetric finite element models were used to model the specimens.

Liu and Weyers ${ }^{12}$ (see also Liu $^{13}$ ) used slabs with chloride admixed in the concrete. Three of them cracked; all of them had been stored outside. The slabs had the dimensions $1180 \mathrm{~mm} \times 180 \mathrm{~mm} \times 216 \mathrm{~mm}$, and contained five rebars of diameter $16 \mathrm{~mm}$ with covers of 25, 51 and $76 \mathrm{~mm}$. The corrosion was measured both by corrosion rate measurements, and by the weight loss method when cracking had occurred. Here the corrosion at cracking measured by the weight loss method was used. Slices of the slabs were analysed, also using the symmetry lines so that only half the reinforcement bar and half the distance to the next reinforcement bar were modelled; see Fig. 5.

Rasheeduzzafar et al. $^{14}$ have carried out current induced accelerated corrosion tests and measured the time to cracking for specimens with cover-to-bar ratios ranging from 0.63 to 4.53 . The corrosion penetration at cracking was measured by the weight loss method, and each value is an average of three tests. Here, slices of the specimens were analysed, using the symmetry line so that only half the reinforcement bar was modelled. Hence, the models looked similar to the one shown in Fig. 5, but without the support shown on the left side in the figure.

The results from all of the analyses of corrosion cracking tests are summarised in Fig. 6, where the corrosion penetration at cracking obtained in the analysis divided by the corrosion penetration at cracking measured in the experiments is plotted versus the cover-to-bar ratio. As can be seen, the extreme values of the scatter are 0.53 and 2.35 . However, most of the analyses show good agreement with the measured values, with values close to 1.0. Since the tests of Andrade et al., ${ }^{8}$ Ghandehari et al., ${ }^{5}$ Al-Sulaimani et $a l .{ }^{7}$ and Cabrera and Ghoddoussi ${ }^{6}$ were used to give the structural behaviour of the rust in the previous

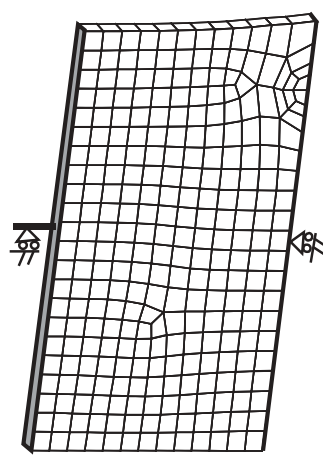

Fig. 5. Finite element model used for analyses of the test specimen of Liu ${ }^{13}$ with cover $25 \mathrm{~mm}$, deformed shape

Magazine of Concrete Research, 2005, 57, No. 7 


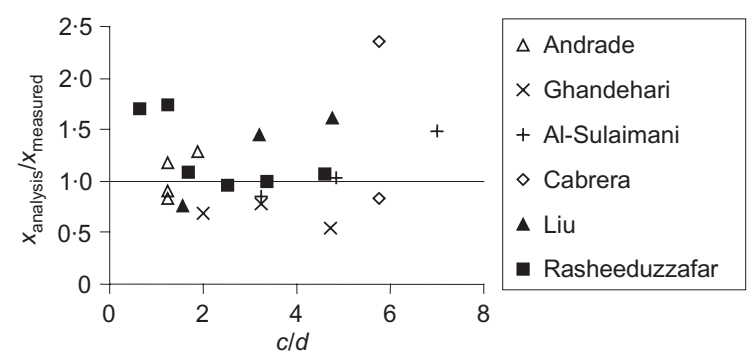

Fig. 6. Comparison between corrosion penetration at cracking obtained in the analyses and in experiments versus the cover-to-bar ratio

section, a good correlation between measured and analysed values is expected for these. However, also the analyses of the tests done by Liu and Weyers ${ }^{12}$ and Rasheeduzzafar et al. ${ }^{14}$ show good agreement with the measured value of the corrosion penetration at cracking.

The main parameters of the corrosion model influencing these results are the ones describing the structural behaviour of the rust, namely the stiffness $K_{\text {cor }}$ and the parameter $p$. As these analyses show reasonable agreement with test results, especially when considering the large scatter that is obtained in such tests, these parameters appear to be well adjusted. An interesting detail of the results is to compare the effect of the storage. The specimens of Andrade et al. ${ }^{8}$ and Cabrera and Ghoddoussi ${ }^{6}$ were dry-stored, the specimens of $\mathrm{Liu}^{13}$ were stored outside, and the others were wet- stored. Studying the results in Fig. 6, there appears to be no significant difference between specimens that were stored wet or dry.

\section{Specimens without transverse reinforcement}

Specimens without transverse reinforcement were analysed to check the capability of the combination of the corrosion model and the bond model. Pull-out tests carried out by Ghandehari et al. ${ }^{5}$ and Almusallam et $a l .{ }^{15}$ were analysed. The pull-out tests of Ghandehari et $a l .{ }^{5}$ were $50 \mathrm{~mm}$ slices that were subjected to accelerated constant current corrosion for 4 weeks. The rebar in each slice was tested in pull-out to investigate the bond strength after $0,1,2,3$ and 4 weeks of corrosion. The corrosion penetration was evaluated both by using Faraday's law from the applied current, and by measuring the weight loss for the reinforcement in each slice. Here, the measured corrosion penetration (evaluated from the weight loss) was used as input.

Axisymmetric finite element analyses were carried out, with the specially developed interface elements describing the corrosion of the reinforcement bar and the bond mechanism. In the analyses, the corrosion was first applied as time steps. When the corrosion penetration measured in the experiments was reached, the reinforcement bar was pulled out of the concrete cylinder. From each of the pull-out analyses, the maximum load was compared with the maximum load obtained when the reinforcement was uncorroded. In Fig. 7, a comparison between the measured bond strengths and
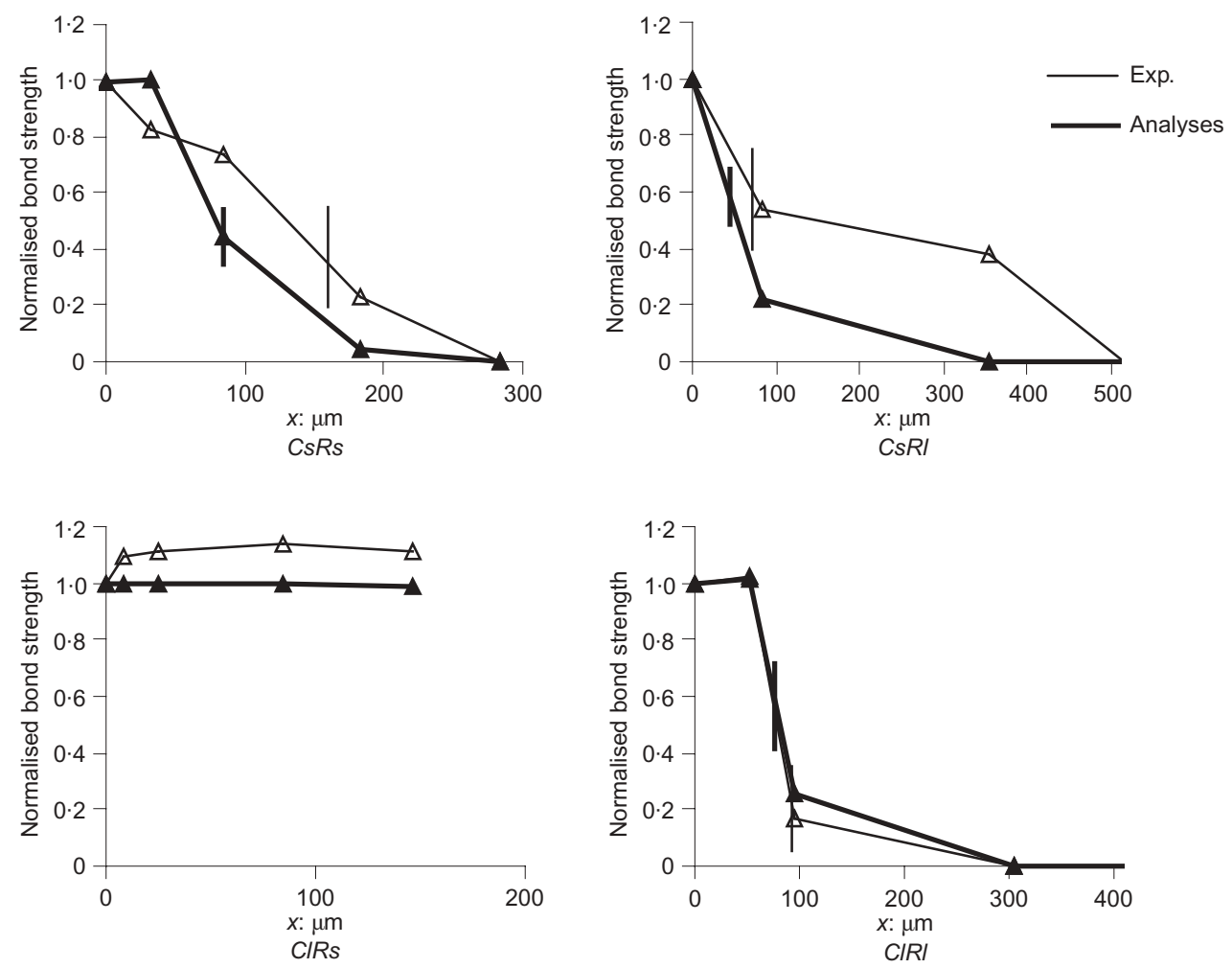

Fig. 7. Comparisons of normalised bond strength, measured and obtained in the analyses versus the corrosion penetration. The vertical lines indicate when cracking penetrated the cover. Experimental results from Ghandehari et al. ${ }^{5}$ 
those from the analyses is shown. The corrosion penetration when cracking penetrated the cover is also marked. As can be seen, the agreement between the tests and the analyses is rather good.

Almusallam et al. ${ }^{15}$ carried out cantilever bond tests. Their specimens were $152 \mathrm{~mm} \times 254 \mathrm{~mm} \times 279 \mathrm{~mm}$, and had a $12 \mathrm{~mm}$ dia. bar with $102 \mathrm{~mm}$ embedment length. Current was used to subject the specimens to accelerated corrosion to varying levels; thereafter bond tests were conducted, and the corrosion penetration was measured by the weight loss method. The finite element mesh used for the analyses is shown in Fig. 8, together with cracks that appeared in the analyses due to corrosion.

At a corrosion penetration of about $150 \mu \mathrm{m}$, a crack appeared from the reinforcement bar to the upper edge in Fig. 8. This corresponds well with the findings in the tests, in which the first crack (to the upper edge) was noted at a corrosion penetration of $140 \mu \mathrm{m}$. The failure mode for the subsequent pull-out force was, both in the test and in the analysis, rather similar to pull-out failure. This can be seen in Fig. 9, since the capacity is still about the same as for the uncorroded specimen. For an increased corrosion penetration to about $175 \mu \mathrm{m}$, still the only crack that had reached the outer edge in the analyses was the upper one. In the subsequent pull-out, however, the right crack reached the edge, and thus the failure mode turned to splitting failure. For a corrosion penetration of $200 \mu \mathrm{m}$, the left crack reached the edge for the corrosion only. As can be seen in Fig. 9, the pull-out capacity is then very low, and does not decrease more even for very large corrosion penetrations, either in the analyses or in the tests. Gen-

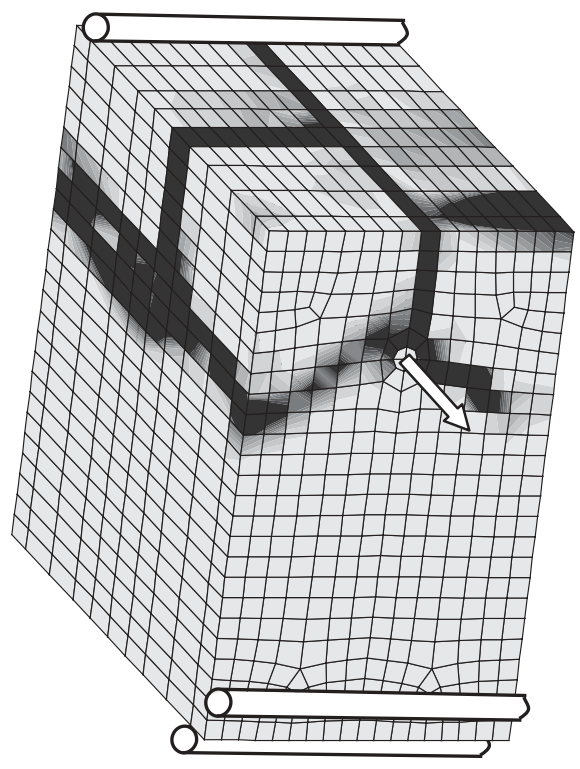

Fig. 8. Finite element mesh used for the analyses of the cantilever bond tests of Almusallam et al. ${ }^{15}$ Regions marked dark grey indicate cracks. These are results from an analysis with an applied corrosion penetration of $377 \mu \mathrm{m}$

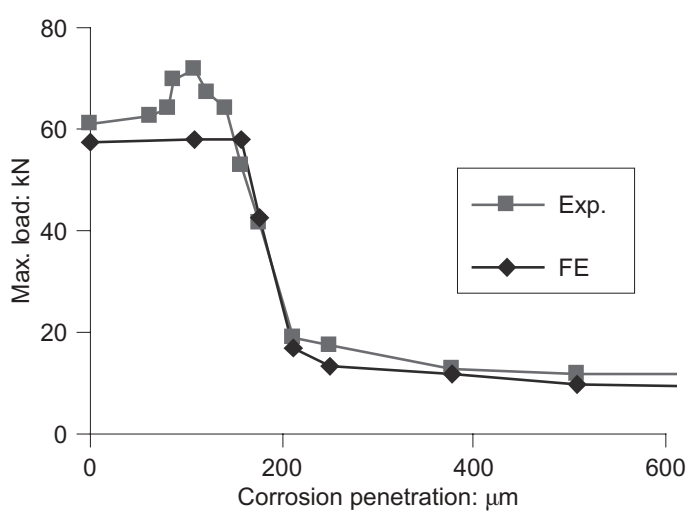

Fig. 9. Comparison of maximum loads obtained in analyses and in cantilever bond tests of Almusallam et al. ${ }^{15}$

erally, the agreement between the analyses and the test results is very good. The only difference is that in the tests, there was an increase in the capacities for corrosion penetrations that did not cause cracking. In the analyses, there is an increase, but it is very small (from 57.7 to $57.9 \mathrm{kN}$ ), and therefore not visible in Fig. 9. In Fig. 10, the load versus slip curves from some of the analyses and tests are compared.

\section{Specimens with transverse reinforcement}

Specimens with transverse reinforcement tested by Coronelli ${ }^{16}$ were analysed. He carried out beam tests following the recommendations by RILEM, but with reduced amounts of transverse reinforcement. Two of his test series were analysed here: the first with concrete cover $50 \mathrm{~mm}$, and the fourth series where the cover was reduced to $35 \mathrm{~mm}$. The specimens were subjected to current induced accelerated corrosion to levels ranging from zero to $300 \mu \mathrm{m}$. Thereafter, the beams were loaded in four-point bending, and the mid-span deformation and the slip of the reinforcement were measured. The finite element mesh used for the analyses where the cover was $35 \mathrm{~mm}$ is shown in Fig. 11 . The transverse reinforcement was modelled with embedded reinforcement; that is, complete interaction between the concrete and the reinforcement was assumed - while the main reinforcement was modelled with solid elements, surrounded by interface elements

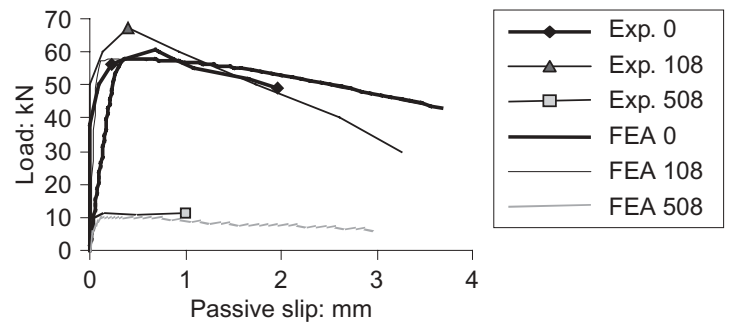

Fig. 10. Load versus slip from analyses and cantilever bond tests of Almusallam et al. ${ }^{15}$

Magazine of Concrete Research, 2005, 57, No. 7 


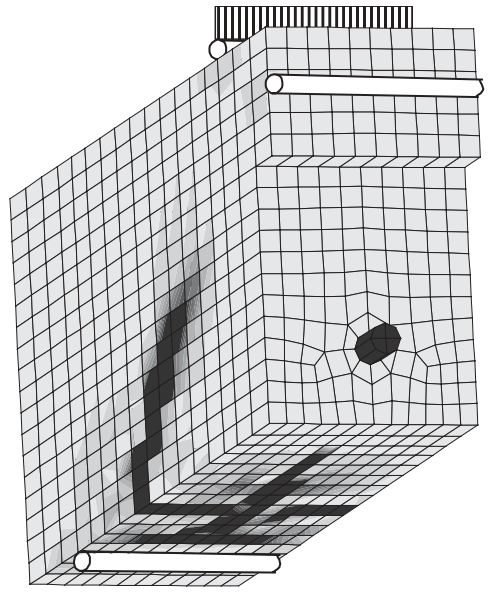

Fig. 11. Finite element mesh used for the analyses of the beam tests of Coronelli ${ }^{16}$ with cover $35 \mathrm{~mm}$. Results shown are from the analysis in which the corrosion penetration was $100 \mu \mathrm{m}$. Dark grey regions indicate cracks at the maximum load

describing the special models for corrosion and bond. In the analyses, the beams were cracked due to the corrosion; for the beams in test series No. 1 with cover $50 \mathrm{~mm}$, cracking of the cover occurred at a corrosion penetration about $85 \mu \mathrm{m}$, whereas for the beams in test series No. 4 with cover $35 \mathrm{~mm}$, a corrosion penetration of about $30 \mu \mathrm{m}$ was enough to crack the cover. This can be compared with the tested beams, in which no cracks could be seen in the first test series (maximum corrosion level was $150 \mu \mathrm{m}$ ), whereas in test series No. 4 the bottom cover cracked at a corrosion penetration around $20 \mu \mathrm{m}$.

The average bond stress along the reinforcement bar at maximum load, from the tests and the analyses, is compared in Fig. 12. As can be seen, the capacity in the tests remained almost unaffected by the corrosion, whereas in the analyses a small decrease occurred. The difference from specimens without transverse reinforcement is observable when comparing the results in Figs
9 and 12. Although cracking of the cover has a serious effect on the bond when there is no transverse reinforcement present, this is not the case when there is transverse reinforcement present which keeps the structure together.

\section{Corrosion cracking}

The effect of uniform or localised corrosion on cracking

Important information for designers is the amount of corrosion that is required to crack the concrete cover. This amount, together with the effect of uniform or localised corrosion on cracking, was investigated. Two three-dimensional models with a reinforcement bar of diameter $16 \mathrm{~mm}$, having a cover of 25 and $76 \mathrm{~mm}$, respectively, in one direction and large cover in the other directions, were analysed; see Fig. 13. The result was then compared to axisymmetric analyses, with the

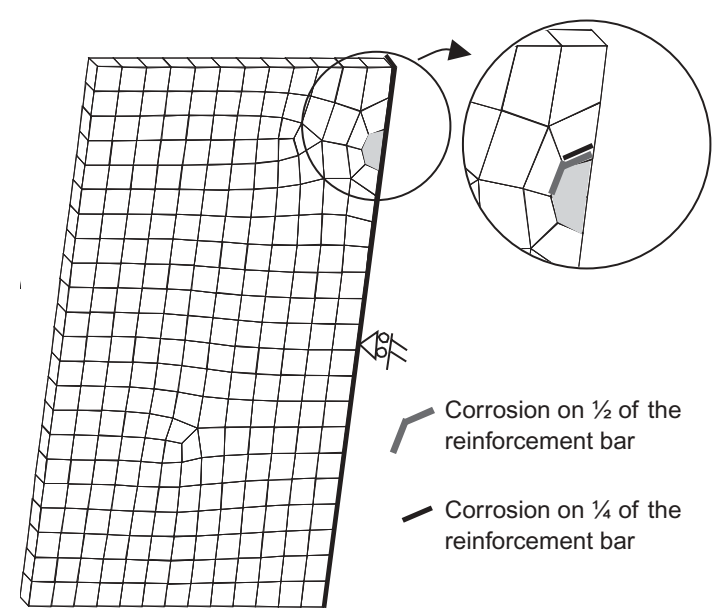

Fig. 13. Finite element mesh used to study the effect of localised corrosion
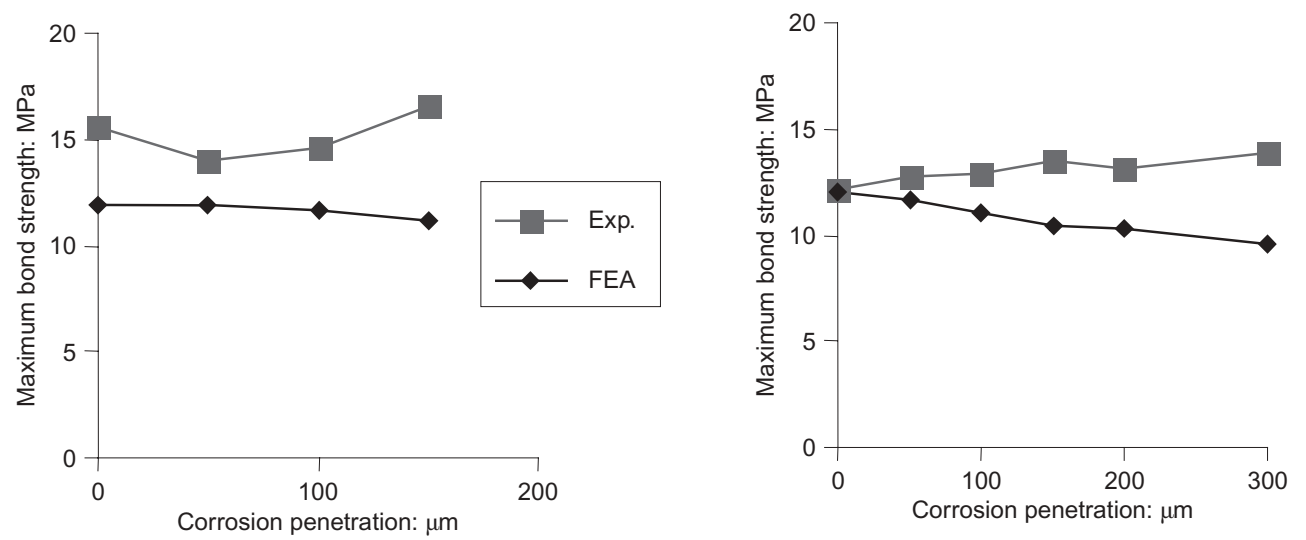

Fig. 12. Comparison of results from tests of Coronelli ${ }^{16}$ and analyses: (a) first test series, cover $50 \mathrm{~mm}$, and (b) fourth test series, cover $35 \mathrm{~mm}$ 
same reinforcement bar diameter and covers, assuming four cracks. In both the three-dimensional and the axisymmetric analyses, the concrete and steel were modelled as described in section 'Comparison with tests, finite element analyses'. A normal-strength concrete was chosen, with a compressive strength of $40 \mathrm{MPa}$ and the maximum aggregate size $16 \mathrm{~mm}$. Neither shrinkage nor creep was included in these analyses.

The effect of non-uniform corrosion was investigated in the three-dimensional models by applying corrosion only in parts of the interface between the reinforcement and the concrete. Two different cases were studied: corrosion on half of the reinforcement bar, and corrosion on one-quarter of the reinforcement bar. In both cases, it was the part of the reinforcement bar closest to the edge that was assumed to corrode. The reason for this choice is that, whether the corrosion is initiated due to chlorides or carbonation, it is the part of the reinforcement bar closest to the edge that will start to corrode first. Petre-Lazar ${ }^{4}$ showed that there were more corrosion products at a crack than at the rest of the surface around a reinforcement bar.

The results are summarised in Table 2. As can be seen, the average corrosion penetration that causes cracking of the cover is approximately the same in the axisymmetric analyses as in the three-dimensional analyses, when uniform corrosion is assumed. Furthermore, when half of the reinforcement bar was assumed to corrode, similar results were obtained. However, when all the corrosion was assumed to take place on only one-quarter of the reinforcement bar, less average corrosion penetration was needed to crack the cover. Furthermore, the crack pattern differed between the different analyses. For all the studied cases, the first crack appeared from the reinforcement bar to the upper edge. For uniform corrosion, this crack then continued to grow. For the large cover and localised corrosion, inclined cracking appeared at a larger corrosion penetration; see Fig. 14. The first crack was then closed, and in reality, this would most likely have caused spalling of the cover.

From these analyses, it was concluded that axisymmetric analyses appear to be a sufficient level of modelling when studying cracking due to uniform corrosion. If localised corrosion is to be studied, threedimensional models need to be used.

Table 2. Average corrosion penetration at cracking in various analyses

\begin{tabular}{l|c|c|c|c}
\hline \multirow{2}{*}{ Cover: mm } & \multicolumn{4}{|c}{ Average corrosion penetration at cracking } \\
\cline { 2 - 5 } & Axisym.: $\mu \mathrm{m}$ & $3 \mathrm{D}^{1}: \mu \mathrm{m}$ & $3 \mathrm{D}^{2}: \mu \mathrm{m}$ & $3 \mathrm{D}^{3}: \mu \mathrm{m}$ \\
\hline 25 & 25 & 22 & 20 & 12 \\
76 & 110 & 110 & 100 & 60 \\
\hline
\end{tabular}

${ }^{1}$ Uniform corrosion.

${ }^{2}$ Corrosion on one-half of the reinforcement bar

${ }^{3}$ Corrosion on one-quarter of the reinforcement bar.
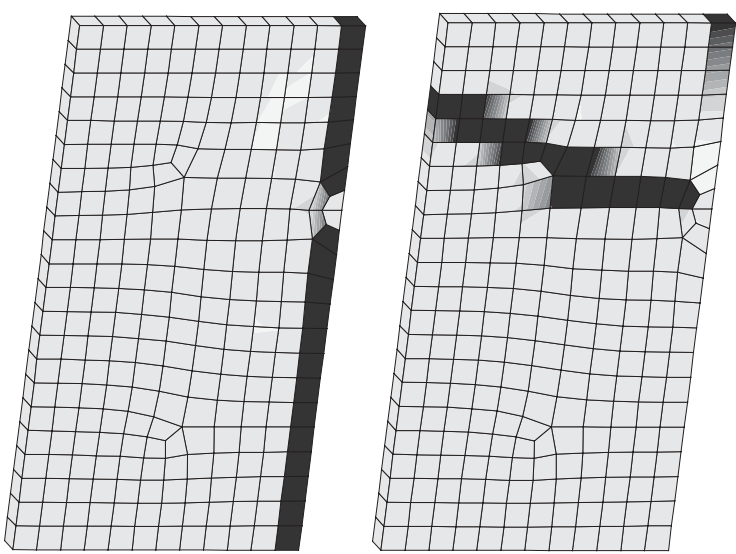

Fig. 14. Crack pattern for (a) uniform corrosion and (b) localised corrosion combined with a large cover. Dark areas indicate cracks

\section{Uniform corrosion}

To study the effect of uniform corrosion, a parameter study using axisymmetric analyses was performed. Again, neither shrinkage nor creep was included in these analyses. The corrosion penetration that caused cracking of the cover for various cover-to-bar diameter ratios is shown in Fig. 15. These results are for a concrete with a compressive strength of $40 \mathrm{MPa}$ and maximum aggregate size $16 \mathrm{~mm}$. As can be seen, the results differ slightly for different bar diameters. The points shown in the diagram are the last ones where cracking was obtained; for larger cover-to-bar diameter ratios, the cover was not cracked regardless of how much corrosion was applied. However, these points are of limited practical use, since they correspond to very large cover-to-bar diameter ratios, much larger than is used in practice.

To show the effect of the quality of the concrete, three different types were used. They all had the maximum aggregate size $16 \mathrm{~mm}$, but the compressive strength was varied, with values 20,40 and $80 \mathrm{MPa}$. The results for the cover-to-bar ratios that are of prac-

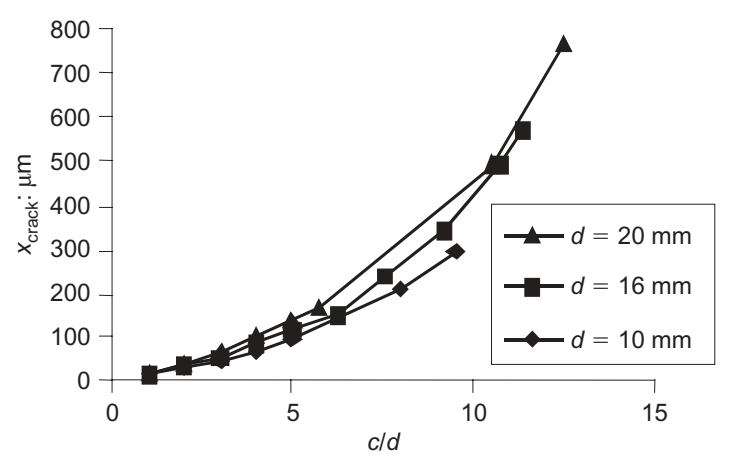

Fig. 15. Corrosion penetration that causes cracking of the cover; uniform corrosion and a concrete with compressive strength $40 \mathrm{MPa}$ and maximum aggregate size $16 \mathrm{~mm}$

Magazine of Concrete Research, 2005, 57, No. 7 
tical interest are shown in Fig. 16. As can be seen, the quality of the concrete has a strong influence on how much corrosion the cover can withstand before it is cracked. Note, however, that it is not actually the compressive strength that has this influence; the main controlling parameter is the fracture energy of the concrete. The latter, however, has been calculated from

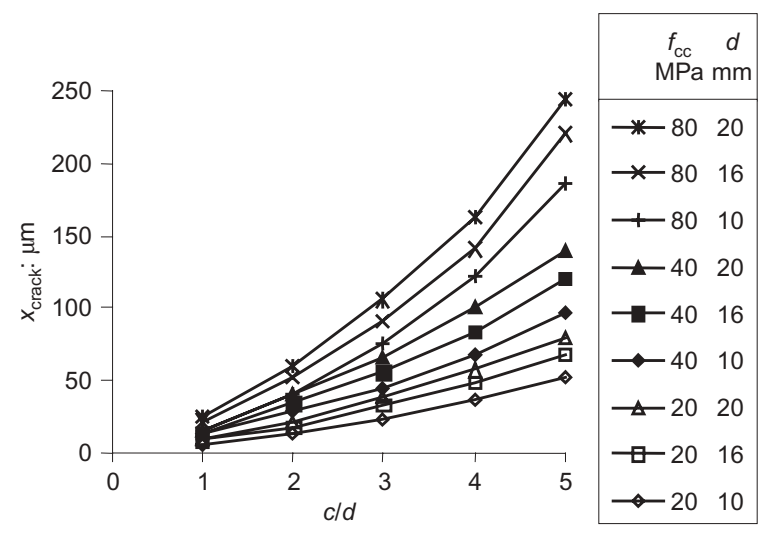

Fig. 16. Corrosion penetration that causes cracking of the cover for various concrete qualities. Uniform corrosion, maximum aggregate size $16 \mathrm{~mm}$ the compressive strength and the maximum aggregate size according to the expressions in CEB. ${ }^{11}$ For the three concrete types used here, the fracture energy was $48 \cdot 7,79 \cdot 2$ and $128 \cdot 6 \mathrm{~N} / \mathrm{m}$.

\section{Anchorage of reinforcement}

To investigate how the anchorage of reinforcement is influenced by reinforcement corrosion, again axisymmetric analyses were carried out. An example of a model is shown in Fig. 17(a). The input for the reinforcement was chosen to be that which was defined as 'normal' in Johansson, ${ }^{17}$ and is shown in Fig. 17(b). Pull-out tests on reinforcement bars with a diameter of $16 \mathrm{~mm}$ and with varying covers were modelled. The embedment length was increased until rupture of the reinforcement bar was the limiting failure. This was done for various corrosion penetrations, and for various concrete covers. No transverse reinforcement was included.

In Fig. 18(a), the anchorage length needed to anchor the bar to rupture is plotted versus the cover-to-bar diameter ratio for different corrosion penetrations. As

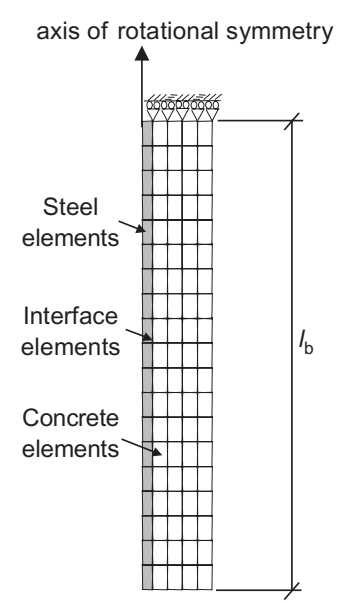

(a)

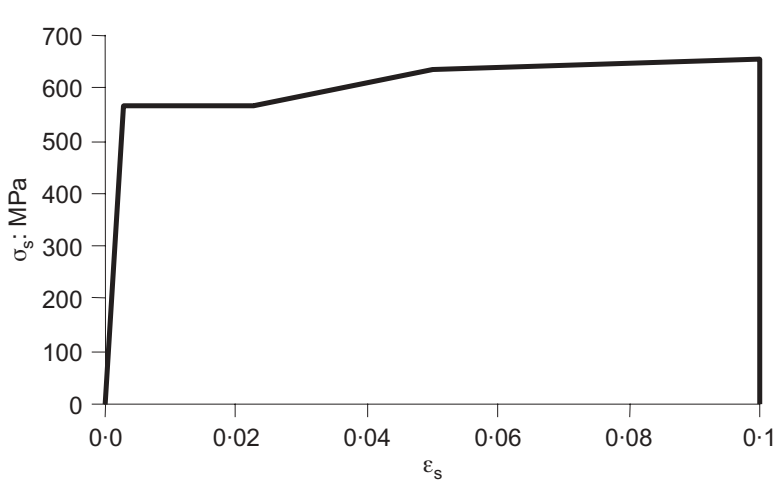

(b)

Fig. 17. (a) Example of an axisymmetric model used to study the anchorage of reinforcement; and (b) chosen input for the reinforcement in these analyses

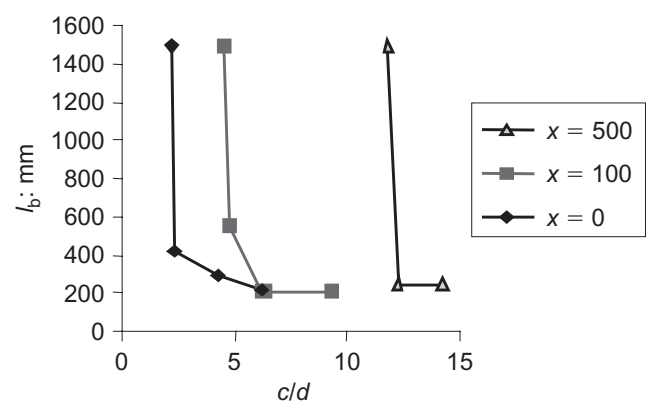

(a)

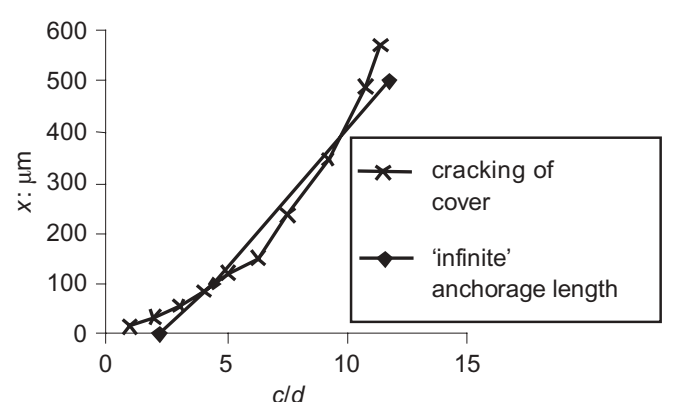

(b)

Fig. 18. Results from analyses without transverse reinforcement. (a) The anchorage length needed to anchor the bar to rupture versus the cover-to-bar diameter ratio for different corrosion penetrations; and (b) corrosion penetration and cover-to-bar diameter ratio that causes 'infinite' anchorage lengths 
can be seen, the anchorage length is about the same for any cover-to-bar ratio, until the cover-to-bar diameter ratio reaches a critical value. Then the anchorage length abruptly becomes very large. The more corrosion, the more abrupt is the increase in anchorage length, and the larger becomes the critical value of the cover-to-bar ratio. The reason for this is that the cover is cracked at a certain level of corrosion. Since there is no transverse reinforcement, it is then not possible to anchor the reinforcement. In Fig. 18(b), the critical value of the cover-to-bar ratio and the corresponding corrosion penetration are compared with the corrosion penetration that causes cracking of the cover, from the analyses in the previous section. As can be seen, they correspond rather well. To conclude: if no transverse reinforcement is present, the anchorage of the reinforcement becomes critical when cracking of the cover occurs. However, cracking of the cover is less critical for a bar in a beam or a slab than these analyses indicate. In the axisymmetric analyses, the cover cracks in all directions at the same time. For a bar in a cross-section, the cover varies in the different directions, and thus some capacity will still remain when the smallest cover is cracked, as can be seen in the analyses of the cantilever bond tests of Almusallam et al. ${ }^{15}$

\section{Conclusions}

The mechanical behaviour of rust was studied by a combination of analyses and test results found in the literature. This led to the assumption that rust behaves like a granular material, that is, its stiffness increases with the stress level. This mechanical behaviour and the volume increase of the corrosion products compared with the virgin steel were modelled in a corrosion layer. By taking the mechanical behaviour of the rust itself into account, the rust obtains a certain strain, and thereby the full volume increase will not be imposed on the concrete. The corrosion layer was combined with a model of the bond mechanism. This bond model includes the splitting stresses of the bond action, and is sensitive to the strength of the surrounding structure.

By combining these models, the effect of corrosion on the bond strength can be analysed for diverse structures, and the effect of varying cover, stirrups, outer pressure, etc., can be investigated. Comparisons between analyses of several corrosion cracking tests, beams and pull-out tests with corroded reinforcement, both with and without transverse reinforcement, and test results found in literature show reasonable agreement. The results indicate that this way of modelling can predict the decrease of bond when splitting of the concrete occurs, due to the combined action of corrosion and the bond mechanism.

The model was used to study the effect of uniform or localised corrosion. It was shown that for localised corrosion, less average corrosion penetration was needed to crack the cover than for uniform corrosion. Furthermore, the crack pattern differed. From these analyses, it was concluded that axisymmetric analyses appear to be a sufficient level of modelling when studying cracking due to uniform corrosion. If localised corrosion is to be studied, three-dimensional models need to be used.

The model was also used to study the effect of uniform corrosion on the anchorage length when no transverse reinforcement is present. In axisymmetric analyses, the anchorage of the reinforcement becomes critical when cracking of the cover occurs. This criterion is on the safe side to use for bars in beams or slabs, as the cover varies in the different directions, and thus some capacity will still remain when the smallest cover is cracked.

\section{References}

1. Lundgren K. Modelling the effect of corrosion on bond in reinforced concrete. Magazine of Concrete Research, 2002, 54, No. 3, 165-173.

2. Lundgren K. Bond between ribbed bars and concrete. Part 1: Modified model. Magazine of Concrete Research, 2005, 57, No. 7, 371-382.

3. Noghabai K. Effect of Tension Softening on the Performance of Concrete Structures. $\mathrm{PhD}$ thesis, Luleå University of Technology, Luleå, Sweden, 1998.

4. Petre-Lazar I. Evaluation $d u$ comportement en service des ouvrages en beton arme soumis a la corrosion des aciers (Aging assessment of concrete structures submitted to steel corrosion, in French). $\mathrm{PhD}$ thesis, Laval University, Quebec, 2000.

5. Ghandehari M., Zulli, M. and Shah S. P. Influence of corrosion on bond degradation in reinforced concrete. Proceedings EM2000, Fourteenth Engineering Mechanics Conference, Austin, Texas, 2000. American Society of Civil Engineers, Reston, VA, 2000, pp. 1-15.

6. Cabrera J. G. and Ghoddoussi P. The effect of reinforcement corrosion on the strength of the steel/concrete 'bond'. Bond in Concrete, Proceedings of an International Conference, Riga, 1992. Comité Euro-International du Béton, pp. 10-11-10-24.

7. Al-Sulaimani G. J., Kaleemullah M., Basunbul I. A. and RASHEEDUZZAFAR. Influence of corrosion and cracking on bond behavior and strength of reinforced concrete members. ACI Structural Journal, 1990, 87, No. 2, 220-231.

8. Andrade C., Alonso C. and Molina F. J. Cover cracking as a function of bar corrosion.1. Experimental test. Materials and Structures, 1993, 26, No. 162, 453-464.

9. FÉdération InTERnational du BÉton. Bond of reinforcement in concrete, State-of-art report. Fédération internationale du béton, prepared by Task Group Bond Models, Lausanne, fib bulletin 10, 2000

10. TNO. DIANA Finite Element Analysis, User's Manual release 7. TNO Building and Construction Research, The Hague, 1998.

11. Comité Euro-International du Béton. CEB-FIP Model Code 1990. Bulletin d'Information 213/214, Lausanne, Switzerland, 1993.

12. LiU Y. P. and Weyers R. E. Modeling the time-to-corrosion cracking in chloride contaminated reinforced concrete structures. ACI Materials Journal, 1998, 95, No. 6, 675-681.

13. LIU Y. Modeling the time-to-corrosion cracking of the cover concrete in chloride contaminated reinforced concrete structures. $\mathrm{PhD}$ thesis, Virginia Polytechnic Institute and State University, Blacksburg, Virginia, 1996.

14. Rasheeduzzafar, Al-Sahdoun S. S. and Al-Gahtani A. S. 
Corrosion cracking in relation to bar diameter, cover, and concrete quality. Journal of Materials in Civil Engineering, 1992, 4, No. 4, 327-342.

15. Almusallam A. A., Al-Gahtani A. S. and Aziz, A. R. Effect of reinforcement corrosion on bond strength. Construction and Building Materials, 1996, 10, No. 2, 123-129.

16. Coronelli D. Bar Corrosion in Steel-concrete Bond: Material and Structural Effects in $R / C$. PhD thesis, Politecnico di Milano, Milano, 1998.
17. Johansson M. Armeringsseghetens inverkan på deformationsförmågan hos betongkonstruktioner - Olinjär finit elementanalys (in Swedish). Concrete Structures, Chalmers University of Technology, Göteborg 97:1, 1997.

Discussion contributions on this paper should reach the editor by 1 March 2006 